\title{
Article \\ Stratification Analysis and Behaviour of a Real Industrial Thermocline Thermal Energy Storage Tank for Cogeneration Purposes
}

\author{
Francisco J. Fernández ${ }^{1, * \mathbb{D}}$, José Díaz ${ }^{1}$ D , María B. Folgueras ${ }^{2}$ (D) and Inés M. Suárez ${ }^{1}$ \\ 1 Polytechnic School of Engineering, University of Oviedo, C/Wifredo Ricart s/n, 33204 Gijón, Spain; \\ diazjose@uniovi.es (J.D.); ines@uniovi.es (I.M.S.) \\ 2 School of Mining, Energy and Materials Engineering, University of Oviedo, C/Independencia, 13, \\ 33004 Oviedo, Spain; belenfd@uniovi.es \\ * Correspondence: javierfernandez@uniovi.es; Tel.: +34-985-182-112
}

Citation: Fernández, F.J.; Díaz, J.;

Folgueras, M.B.; Suárez, I.M.

Stratification Analysis and Behaviour

of a Real Industrial Thermocline

Thermal Energy Storage Tank for

Cogeneration Purposes. Processes

2021, 9, 120. https://doi.org/

$10.3390 /$ pr9010120

Received: 3 December 2020

Accepted: 6 January 2021

Published: 8 January 2021

Publisher's Note: MDPI stays neutral with regard to jurisdictional clai$\mathrm{ms}$ in published maps and institutional affiliations.

Copyright: $(\odot 2021$ by the authors. Licensee MDPI, Basel, Switzerland. This article is an open access article distributed under the terms and conditions of the Creative Commons Attribution (CC BY) license (https:// creativecommons.org/licenses/by/ $4.0 /)$.

\begin{abstract}
Thermal energy storage systems help to couple thermal energy generation and process demand in cogeneration facilities. One single deposit with two design temperatures and one main temperature step in sensible thermal energy storage define the thermocline systems. Performance of one high size real thermocline thermal energy storage system is analysed. Starting from temperature and mass flow rate data registered by the plant control system, one advanced thermodynamic analysis is performed. The quality of heat storage is analysed in terms of evaluation of the stratification in the thermocline zone. The temperature data registered at 21 positions is extended by displacement analysis generating detailed profiles. Fraction of recoverable heat, thermocline width, stratification indices based on energy and exergy analysis, and mean temperature gradients in the thermocline region are calculated. These parameters are monitored under real operation conditions of the plant. The calculated parameters are studied to check their distribution and correlation. First and Second Law indices show parallel behaviour and two values are found that delimit situations of high and low values of mean temperature gradients. It was observed that buoyancy generates uniform forced movement with the right water temperature entering the diffusers, but good control strategies are essential to avoid mixing. The system demonstrated great stability in this use.
\end{abstract}

Keywords: thermocline; thermal energy storage; stratification index; combined heat and power

\section{Introduction}

Technologies for thermal energy storage (TES) allow mismatching between thermal energy sources and demands, so they have special value in systems in which energy availability and demand do not coincide in size or time. As thermal storage decouples production and demand, it provides flexibility that can be decisive to make many projects viable. The thermal energy can be stored by modifying the internal energy of accumulated materials. This change can be made as the latent heat in a phase change $[1,2]$ or by temperature variation as sensible heat $[3,4]$. When the sensible heat is stored in a single tank, the system takes advantage of the stratification. The hot fluid rests stable in the upper layers of the tank while the denser cold fluid stays in its lower part. If the hotter and colder temperatures are approximately constant, there is a temperature step in height between cold and hot zones called thermocline.

TES systems are very appropriate for combined heat and power (CHP) facilities $[5,6]$. In $\mathrm{CHP}$, at least two types of energy are generated in the same process. The production of electricity and thermal energy can be conditioned by the electric demand or its sale to the power grid. These plants are much more flexible when there is availability of storage for the generated thermal energy. Christidis et al. [7] optimized heat storage devices together with the operation of CHP plant in a district heating. Smith et al. [8] also studied the benefits of combining TES with CHP in commercial buildings. 
Thermal solar facilities used to count with TES systems [9-12]. Sensible heat storage technology has interest for the solar power plant industry $[10,13]$. In these plants thermal energy is accumulated at high temperature levels, so molten salts or thermal oils are used as the energy transfer and storage fluids. To complete the capacity of these fluids, filler materials are usually employed in packed bed accumulators [14-16]. For lower storage temperature, water is a good option to be used as storage fluid. It is cheap, available, clean, and it has a high specific thermal capacity. If temperatures reach values above $100{ }^{\circ} \mathrm{C}$ the system must be pressurized to avoid vaporization. Big interest remains active in solar thermal energy utilisation nowadays to reduce energy demand in buildings [17] and industry [18].

Big thermal energy storage systems will surely have to be included in the building energy management systems in the future as well as in the smart city energy systems, heating, and cooling applications $[19,20]$. TES systems are essential in domestic hot water applications [21,22].

In thermocline tanks for TES, zones of water with high and low temperatures are adjacent and there are no division elements between them. As a result, the energy can be transferred through several ways from hot to cold region and then a part of the stored energy can be lost. The behaviour of thermocline thermal energy storage systems has been analysed in terms of the evaluation of stratification in lots of studies [23,24]. Studies from Dincer et al. [3] together with Zurigat and Ghajar [4] are examples of benchmark references in the field of sensible heat storage systems. They set important criteria about the use of First and Second Law analysis to evaluate the stratification in TES systems. The particular importance of exergy analysis in the evaluation of stratification was highlighted in very important studies by Rosen et al. [25,26]. Haller et al. [23] studied the different methods to characterise thermal stratification in thermal energy storage. Jack and Wrobel [27] performed one thermodynamic optimisation to determine optimal design parameters through exergy analysis and dynamical study applied to one analytically solvable model. Fan and Furbo [28] investigated thermal stratification by means of computational fluid dynamics analysing the effect of design and flow parameters on the tank stratification. Flueckiger and Garimella [29] performed one Second law analysis of stratification in a molten-salt cyclic operation energy storage system from a solar thermal power plant.

Energy storage technologies are of the utmost importance these days. Energy transition for achieving decarbonisation goals will have to be applied not only to electrical but also to thermal systems. The noncontrollable availability of renewable energy sources together with the limited capacity of electrical energy storage technologies encourage us to pay attention to the thermal energy storage technologies. Advanced energy systems can include both electrical and thermal energy storage. Combination of CHP with thermal and electrical energy storage was evaluated with result of important energy savings [30]. The operation optimisation in one TES in an industrial cluster was studied by Thombre et al. [31]. TES processes must be studied in depth when they are included in complex energy management systems. The appropriate way to do this is through exergy, Second Law analysis, as it was confirmed in our results.

Information about thermal energy storage is available from industry, where huge amounts of energy has been stored for decades. In spite of it, available data from real industrial thermal energy storage systems operation was not found in the specialised literature.

In this study, one real industrial thermocline thermal energy storage (TTES) system that uses water as sensible heat storage medium in a CHP plant is analysed. Real data was acquired from this real scale industrial TTES plant. The analysis started from the available information in the conventional plant control system. Temperature and mass flow rate records were provided by the plant data acquisition system. Data was processed to obtain valuable information about the detailed temperature profile and the system behaviour. After that, some analytical tools available from theoretical and experimental studies were selected and in some cases adapted for the system analysis. Fraction of recoverable heat was calculated and five indices were used for the evaluation of the tank 
stratification: thermocline width, First Law Index, Second Law index, and two thermocline mean temperature gradients. These analytical tools have not yet been applied to one real industrial thermal energy storage plant. Thanks to that, the plant was studied through First and Second Law criteria. Besides, the operational procedures gave important information about the way it is operated and their effect on the behaviour of the thermocline zone.

One of the objectives of this work is to extend the available information by means of data processing and the use of indices to check the TTES performance under real working conditions. The operational data in a real scale plant improves the knowledge of these systems substantially and gives relevant information in the thermal energy storage field. Deep analysis was performed from limited information available from conventional control systems. Appropriate tools and procedures to evaluate stratification quality have been selected that can be applied in energy studies including thermocline thermal energy storage systems.

\section{Materials And Methods}

\subsection{Thermal Energy Storage System}

In this study, one tank installed in a CHP plant is analysed. Thermal energy is stored as sensible heat of pressurized liquid water. To avoid loss of stratification caused by inlet flows, double ring octagonal diffusers are placed in the upper and lower water inlets [32]. The cylindrical deposit has semielliptical heads. It is $25 \mathrm{~m}$ high with a total capacity of $810 \mathrm{~m}^{3}$. It is constructed in steel with a $100 \mathrm{~mm}$ thickness thermal isolation.

The thermal energy storage is performed with design high and low temperatures of $125{ }^{\circ} \mathrm{C}$ and $54{ }^{\circ} \mathrm{C}$, respectively. During the charging phases, water enters at high temperature through the upper inlet diffuser and exits at low temperature through the lower diffuser. The discharging process consists of the low temperature water entering the deposit through the lower diffuser and high temperature water exiting through the upper tank conducts. Hot and cold zones are separated by the thermocline region.

The thermal storage tank is placed between the energy production and consumption systems, as it is schematically shown in Figure 1. The source is an internal combustion engine and the demand is a conventional drying process. Thermal power and working schedules of both subsystems do not match, then successive charging, discharging, and storing periods happen with different values of inlet and outlet mass flow rates. Thermal storage studies use systems working with stable conditions, full charging-discharging cycles, and constant flow rates for analysis. The monitoring of this real TTES facility shows a complex combination of different operating modes.

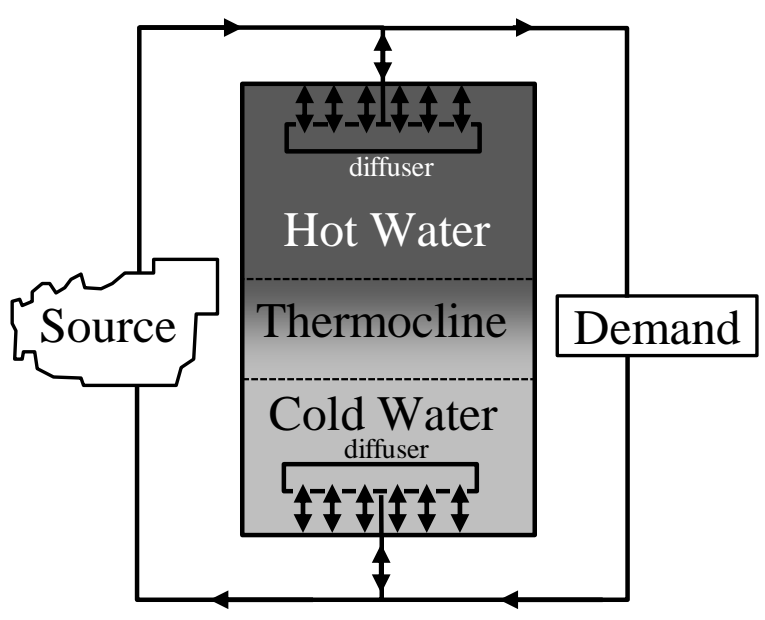

Figure 1. Connection scheme of a thermal energy storage system. 
The charge-discharge periods and the water temperature profile inside the tank can be monitored by means of the process data acquisition system. There are 23 temperature sensors, one in the lower and other in the upper connection pipes, named $T_{p, l o w}$ and $T_{p, h i}$, respectively. The remaining 21 sensors $\left(T_{1} \ldots T_{21}\right)$ are placed inside immersion sleeves uniformly distributed along the cylindrical section of the tank, as schematically represented in Figure 2. The volume flow meter indicates positive values for charging and negative for discharging flows.

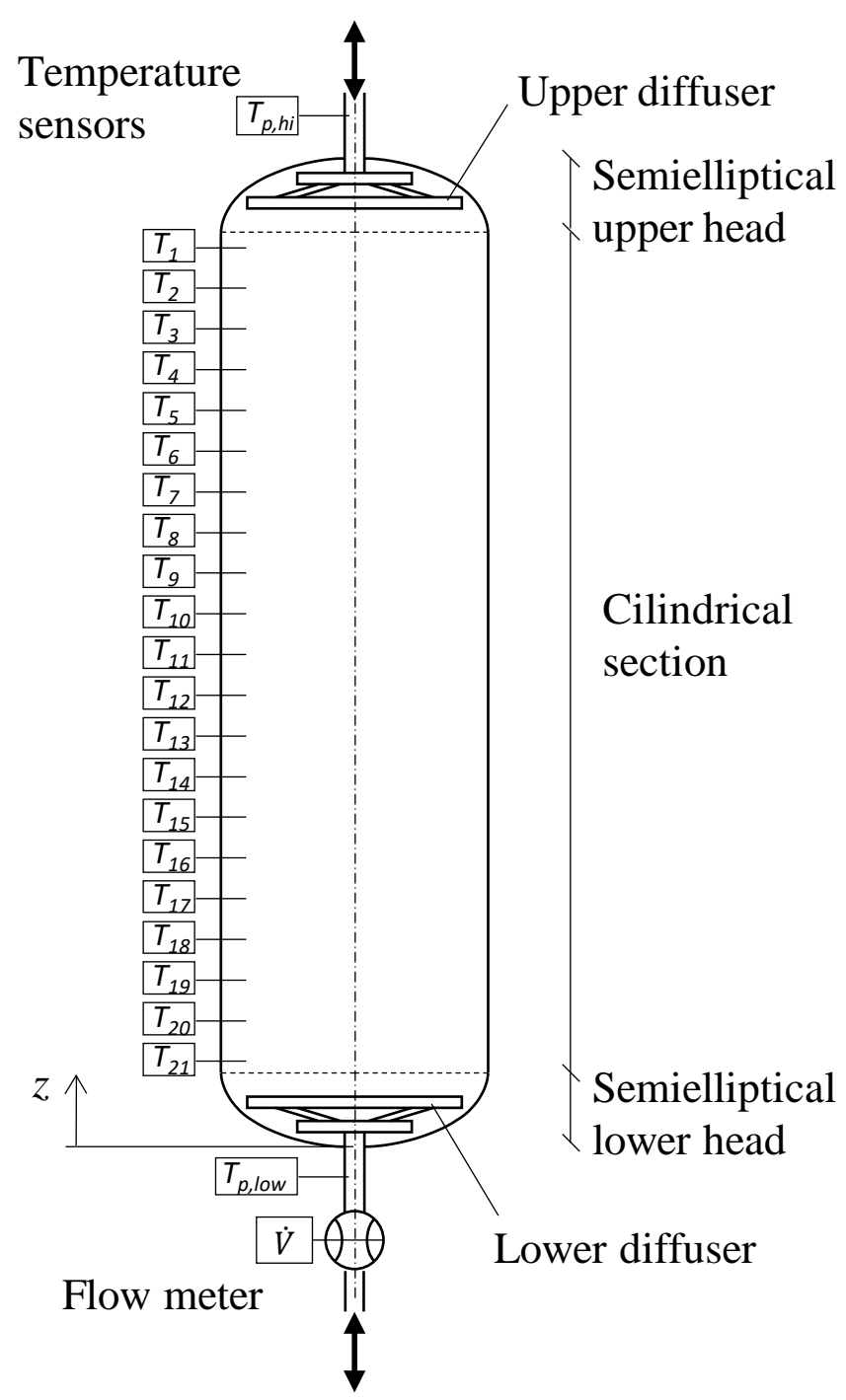

Figure 2. Thermal energy storage device with the sensors of the process data acquisition system.

Data in Figure 3 was obtained from the acquisition system. It is represented by means of charts with the time evolution of the flow rate and pipe temperatures. Instant profiles from the immersion temperature sensors are also represented. Profiles in Figure 3 correspond to one representative $24 \mathrm{~h}$ period in which three different situations happen. They were: one approx $9 \mathrm{~h}$ charge period, one $11 \mathrm{~h}$ discharge, and a final storing period. Positive flow rates can be observed during the first $9 \mathrm{~h}$ in Figure $3 \mathrm{a}$. Hot water enters the upper diffuser with the represented temperature an flow rate. At this instant flow changes to negative values corresponding to the discharge with a flow near to $20 \frac{\mathrm{m}^{3}}{\mathrm{~h}}$ entering the lower diffuser. Mass flow rate and inlet temperature fluctuate for two hours under the control system commanding. Almost two hours of zero mass flow rate that are at the end of the $24 \mathrm{~h}$ period correspond to the storing part of the period. 


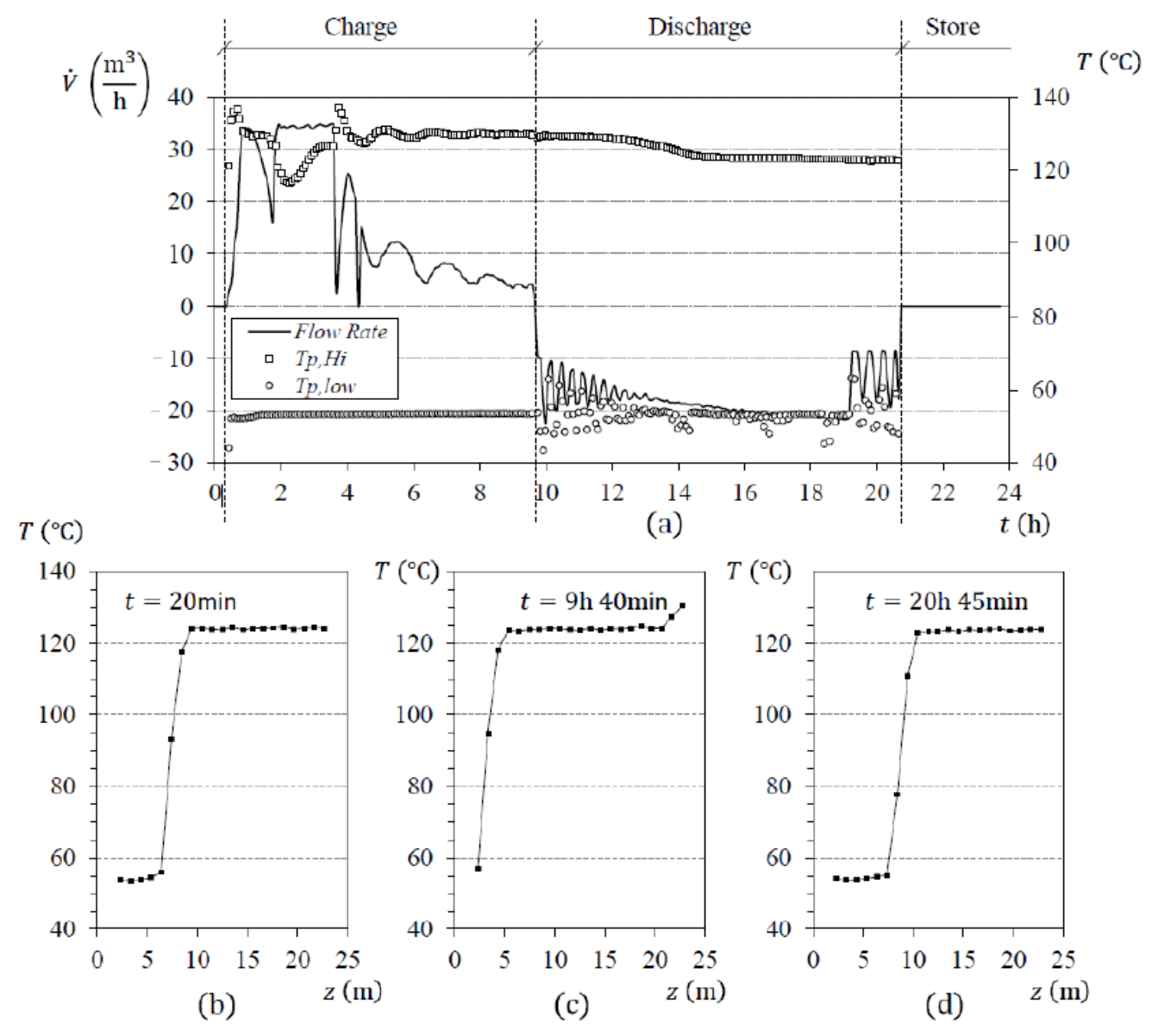

Figure 3. (a) Flow rate and pipe temperatures in a $24 \mathrm{~h}$ period with charging, discharging and storing periods; Temperature profiles at: (b) the beginning of charge; (c) after the charge and (d) after the discharge periods.

Temperature profiles in Figure $3 \mathrm{~b}-\mathrm{d}$ correspond to the beginning of the charge, the instant between charge and discharge, and the end of the discharge period. The upper and lower pipe temperatures are not represented during the storing period. The reason is that under stagnant conditions its value is strongly influenced by the surrounding temperature.

Observing the evolution of the flow rate and pipe temperatures in Figure 3, it can be deduced that real charge and discharge conditions can be far from ideal in these devices. Flows and inlet temperatures are irregular. They are conditioned by the specific characteristic of thermal energy delivery from the generating equipment and the control system of the plant. The shape of the charge flow and temperature profiles is usual in this plant. The discharge acts under inlet temperature control that causes temperature and flow fluctuations.

The charge-store-discharge cycle does not correspond to the full capacity of the TTES system. Besides, after the charge period, the lower zone of the thermocline is very near to the lower tank outlet.

Therefore, it can be easily observed that the behaviour of this TTES tank under performance conditions of one real complex process is different from theoretical constant temperature-full charge-discharge ideal cycle.

\subsection{Data Processing}

The variables registered every $5 \mathrm{~min}$ : time, temperatures, and flow rate, constitute the main available data. Performing some edition to these data, useful information can be obtained that will assist in a deeper analysis of the behaviour of this device. 
The flow dynamics in the upper and lower heads and diffusers is complex. In the central cylindrical section, most of the time the flow is dominated by a forced uniform movement generated by inlet-outlet flows. González-Altozano et al. [33] generated detailed temperature profiles from discrete position measurements by means of interpolation of fitting curves. Here the displacement of the temperature profile with uniform flow assumption allows the generation of one detailed enhanced temperature profile. These enhanced temperature profiles permit us the detailed study of the thermocline region.

However, this pattern is combined with the buoyancy effect that gets important when colder water enters through the upper section or hotter water enters through the lower section. In these situations a mixing of the upper hot or the lower cold zones occurs. Simulation of complex flow with this mixing effect requires computer fluid dynamic tools that are out of the scope of this study.

From the available data and using the same kind of uniform displacement analysis, the effective positions of the tank water outlets can be found. This is done from data corresponding to some special situations when the thermocline region exits the deposit. As the outlet water temperature is also being registered, effective outlet positions can be deduced by this procedure.

\subsubsection{Enhanced Temperature Profiles through Displacement Analysis}

The three instant temperature profiles shown in Figure 3 were directly obtained from the plant data acquisition system. The central mass of water in the tank displaces up and downwards due to the charge and discharge processes, then it is possible to deduce one much more precise temperature profile. This is made just generating it by propagation of the temperatures that are being measured at each sensor with the velocity deduced from the volume flow rates and tank cross section.

One dimensional spatial discretization was performed in height dividing the geometry in $N$ cells. In the central cylindrical region, cells have a height of $2 \mathrm{~cm}$. At the tank heads, $\mathrm{z}$ dimension of elements is a bit higher, because constant volume of the cells is kept. This discretization results in the division of the tank height in $N=1175$ cells.

The temperature profiles generated by the displacement procedure corresponding to instants in Figure 3 are shown in Figure 4. The generated profiles fit well with the available discrete temperatures as can be appreciated in the continuous profile of thermocline region. The good knowledge of the detailed profile in the thermocline region is specially important to evaluate the stratification in the tank.

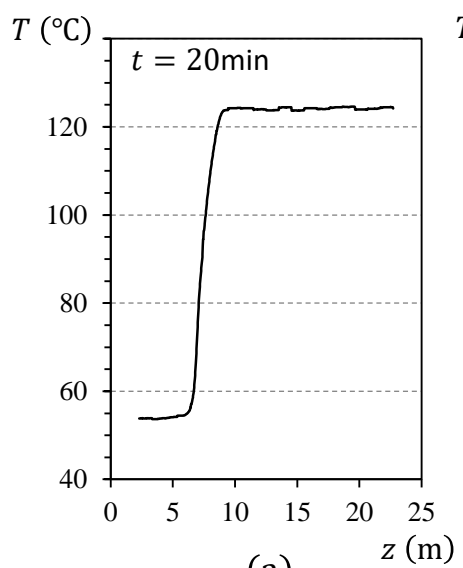

(a)

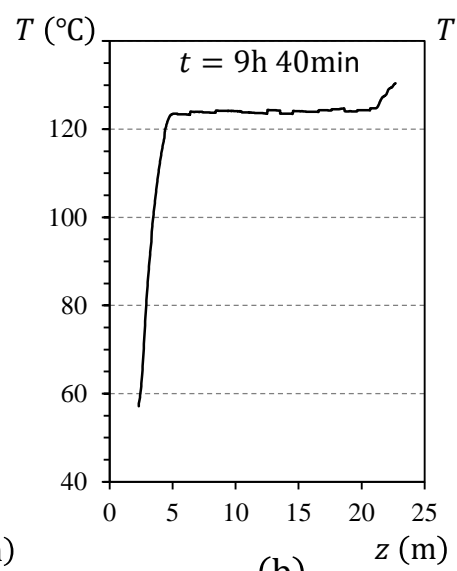

(b)

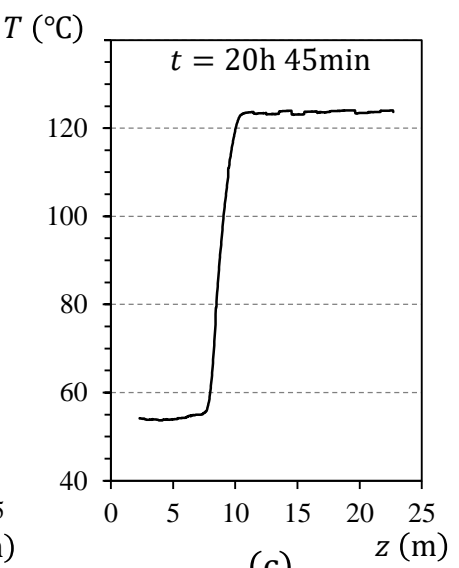

(c)

Figure 4. Detailed enhanced temperature profiles for the instants in Figure 3: (a) the beginning of charge; (b) after the charge and (c) after the discharge periods.

\subsubsection{Effective Outlet Positions}

The flow dynamics in the upper and lower diffusers in the tank heads is complex, due to the stratification and mixing phenomena. The storage of volumes containing the colder 
and hotter liquid combined with the mixing and diffusion of the entering and exiting flows happen.

The complex behaviour of the tank heads could be considered by the assumption of equivalent positions of two effective outlet heights in both extreme regions. There are good opportunities to deduce the effective positions of the tank outlets when charge or discharge processes are complete and the thermocline region reaches the upper or lower exits. The register of pipe temperatures combined with the flow rates and the detailed temperature profile allows the deduction of positions where this effective outlets can be situated in the tank.

The result of the analysis based on the outlet temperatures and the temperature profile is that the effective upper and lower outlets are situated in the positions represented in Figure 5. The events in charts (a) and (b) in Figure 5 were used to deduce these effective positions. Figure 5 a registered data when the thermocline reached the upper diffuser during one complete discharge, causing lower values of $T_{p, H i}$. The analogous situation in Figure 5 happened during one charge when the thermocline reached the lower diffuser causing $T_{p, l o w}$ to increase. One resulting effective storage volume between entrances represents the $95.3 \%$ of the total tank volume.
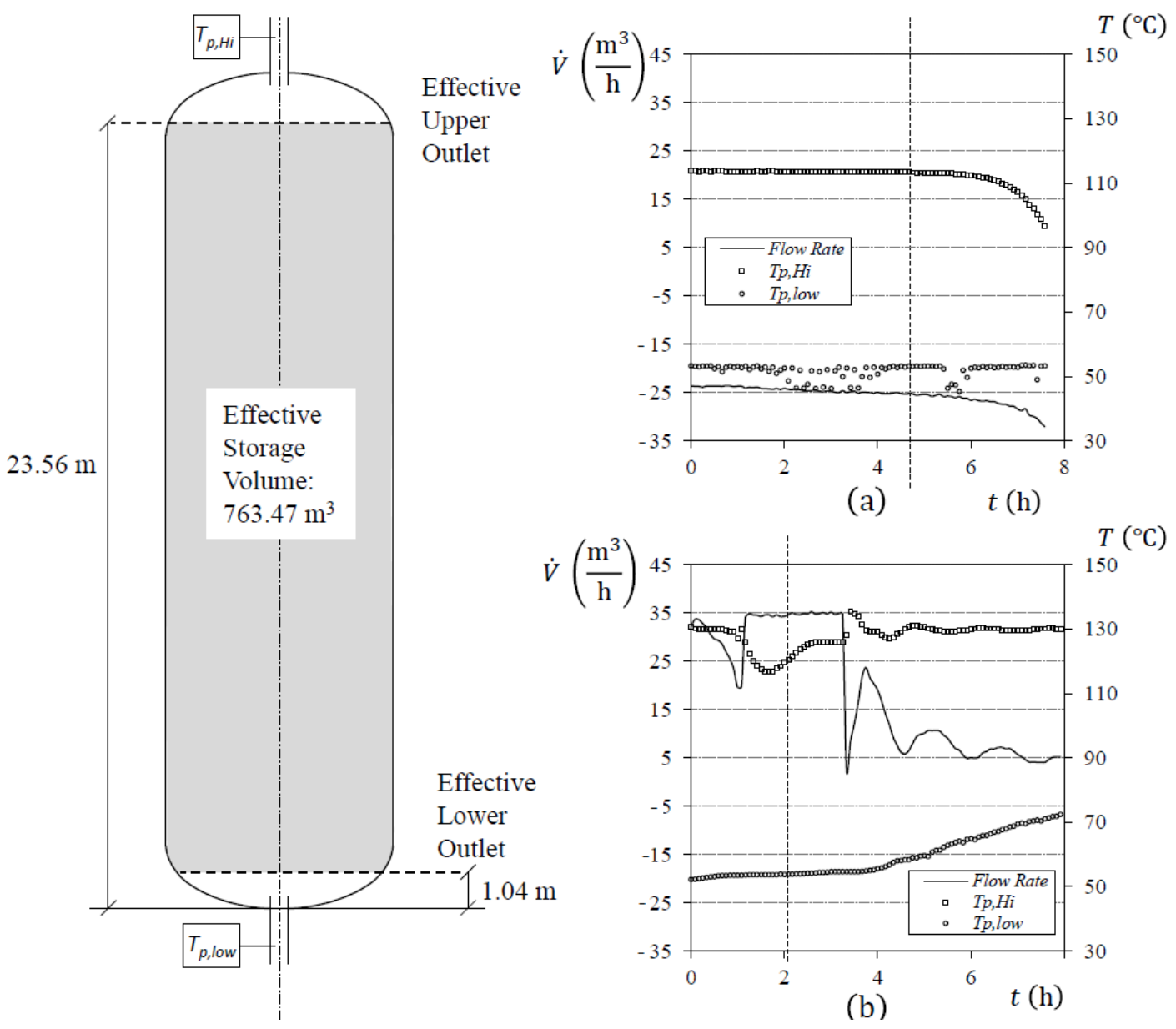

Figure 5. Scheme of the effective outlets and effective storage volume obtained from analysis of periods when: (a) thermocline reaches upper outlet in discharge; (b) thermocline reaches lower outlet in charge.

These effective positions are not real ones and their definitions could help in the study of these two regions when water exits the tank. This happens in the lower head during charge or in the higher head during discharge. The analysis of the tank behaviour through the evolution of the temperature profiles indicate that these positions are not useful to study 
the opposed entering situations. The uncertainty generated by the complex phenomena in extreme tank positions lead to the consideration of the well monitored tank sections, situated between temperature sensors. The deduction of reliable temperature profiles in the extreme regions from the available data was not possible, since not enough match was found with the existing information. The study of the flow in the diffusers is more indicated for studies based on fluid dynamic principles [34,35].

\subsubsection{Fraction of Recoverable Heat}

The fraction of recoverable heat (FRH) was defined by Zurigat and Ghajar [4], also used in $[22,36]$ among others. This index indicates the level of charge in the storage system. In this case, FRH will be calculated based on two design temperatures for the hot and cold tank sections. These are the same as the design inlet and outlet temperatures, fixed as: $T_{H}=125^{\circ} \mathrm{C} ; T_{L}=54{ }^{\circ} \mathrm{C}$. It is calculated as the ratio between the recoverable thermal energy $Q_{R}$, and the storable thermal energy $Q_{S}$. Both energies are evaluated in the central sections between temperature sensors $T_{1}$ and $T_{21}$. The reason for accounting only these positions is that it corresponds with the zone where temperature profiles are reliable. All the indices will be evaluated in the same zone between temperature sensors.

$$
F R H=\frac{Q_{R}}{Q_{S}}
$$

In the domain divided in cells, recoverable heat $Q_{R}$ is obtained by summation of individual energies of each cell $j$ situated between the higher and lower immersion temperature sensor positions, $j_{T 1}$ and $j_{T 21}$ respectively, at heights $z_{T 1}$ and $z_{T 21}$.

$$
Q_{R}=\sum_{j=j_{T 1}}^{j_{T 21}} Q_{j}
$$

The energy of each cell is recoverable if temperature difference with nominal low temperature is higher than $80 \%$ of design temperature difference.

$$
Q_{j}=\left\{\begin{array}{l}
0 \text { if }\left(T_{j}-T_{L}\right)<0.8\left(T_{H}-T_{L}\right) \\
m_{j}\left(h_{j}-h_{L}\right) \text { if }\left(T_{j}-T_{L}\right) \geq 0.8\left(T_{H}-T_{L}\right)
\end{array}\right.
$$

Energy in cell $j, Q_{j}$ is calculated accounting its mass $m_{j}$ and temperature $T_{j}$. The storable thermal energy $Q_{S}$ corresponds to the mass of water between temperature sensors. Enthalpy difference corresponds to temperature change from design high to low temperatures.

$$
Q_{S}=\sum_{j=j_{T 1}}^{j_{T 21}} m_{j}\left(h_{H}-h_{L}\right)
$$

In Equations (3) and (4) calculation of thermal energy is performed in terms of specific enthalpies $h$. Specific enthalpy and density are adjusted from National Institute of Standards and Technology [37] data for liquid water at 5 bar.

\subsection{Evaluation of Stratification}

The stability of stratification is an essential aspect in the TTES tanks. The main reason for loss of stratification in these deposits is the mixing induced by the inlet currents during the charging-discharging periods. Other reason is the generation of convective currents produced by the heat transfer phenomena. The main ways for heat transfer are heat losses to the ambient, axial conduction through the steel walls and heat diffusion through the thermocline [4].

There are lots of ways for the evaluation of the stratification in TES tanks. Bahnfleth and Song [38] used four different parameters to evaluate stratification in a chilled water storage tank. A distinction is made by Haller et al. [23] between parameters that do not 
consider the history of charging-discharging-storing periods, called indices, and efficiencies. The efficiencies compare theoretical full charge-discharge cycles with real ones. The operation mode of the analysed system combines multiple working ways with the absence of clearly defined full charging-discharging cycles. Under these conditions, the application of cycle efficiency parameters is very difficult; some indices will be tested here.

A graphical representation would be the simplest way to show the stratification. Nondimensionalization of temperature and position could improve validity of this graphs, but more quantitative procedures would be desirable. The three main parameters applied are the thermocline width, and two more index, one based in the First and other in Second Laws of Thermodynamics, respectively.

The three stratification indices are obtained from the detailed enhanced tank temperature profile. Only the zone between immersion temperature sensors from $z_{T 1}$ to $z_{T 21}$ is considered. The reason is that entrance streams generates uncertainty in temperature profiles of upper and lower tank heads.

\subsubsection{Thermocline Width}

The thermocline width can be determined by the difference in height of two points that delimit the zone in which the main temperature difference takes place.

Double steps can be generated and other phenomena can appear that affect the tank temperature profile. One procedure was selected to determine the thermocline width trying to avoid sensitiveness to the diverse situations generated during the real plant operation. To do that, the profile is firstly divided in two parts, named cold and hot zones, separated by the thermal level defined by the mean of the design temperatures $\left(T_{M}=89.5^{\circ} \mathrm{C}\right)$. Representative values of the thermal level of hot and cold zones, named $T_{\text {hot }}$ and $T_{\text {cold }}$ are determined by the median of the temperature distribution of each zone. Median is calculated from the profiles from the separation point at $T_{M}$ to the upper and lower temperature sensors, respectively. Differences from $T_{\text {hot }}$ and $T_{\text {cold }}$ are used to find the upper and lower limits of the thermocline zone. In the upper limit, the temperature is below the hot with a difference of $5 \%$ of the cold-hot temperature interval. In the lower limit it is $5 \%$ higher than the cold one, with this percentage defined by the cold-hot temperature interval. As an example to illustrate this procedure, the thermocline definition of the profile in Figure 4c is included as Figure 6a.

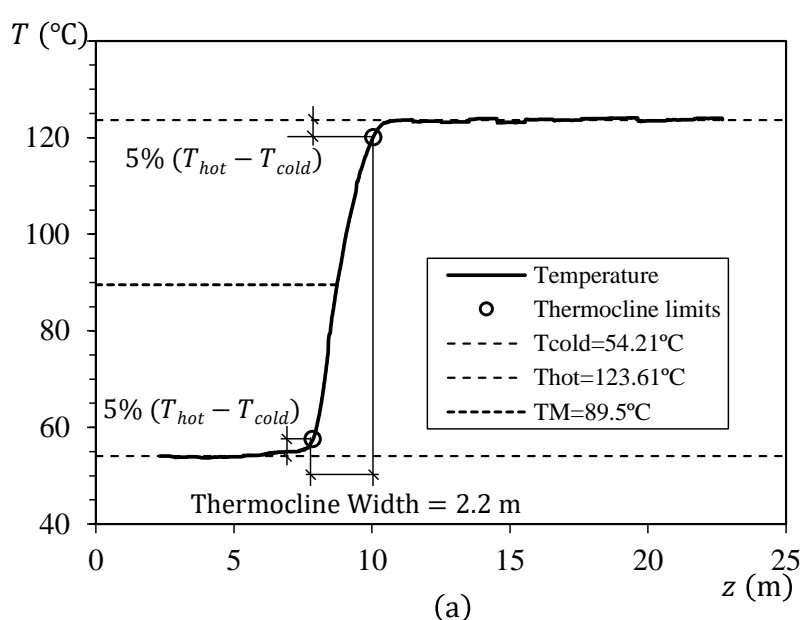

(a)

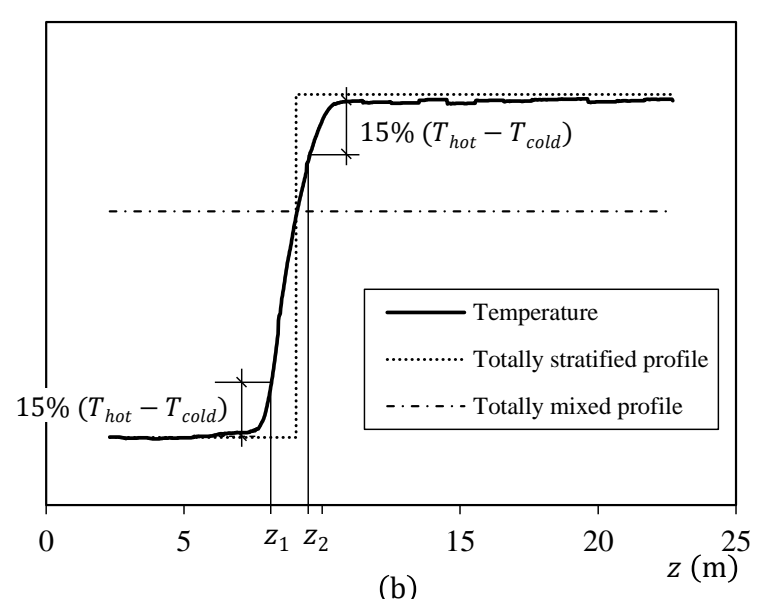

(b)

Figure 6. Example of determination from temperature profile of: (a) thermocline width; (b) heights $z_{1}, z_{2}$ for First Law index $I_{1 L}$, totally mixed and totally stratified profiles for Second Law index $I_{2 L}$. 


\subsubsection{Stratification Index Based on Energy Analysis}

Based on energy analysis, this parameter could also be considered as one First Law Index: $I_{1 L}$. It does not analyse full charging-discharging cycles, but its calculation can be performed from the enhanced temperature profile.

As a first step to evaluate the energy potential of the actual temperature profile, two zones are defined in the tank. The procedure is similar to that performed during the thermocline width determination. Intervals are illustrated in Figure $6 \mathrm{~b}$ corresponding to the temperature profile in Figure $4 \mathrm{c}$. The hot and cold temperatures $T_{\text {hot }}$ and $T_{\text {cold }}$ are used to define two regions. In this case differences of $15 \%$ of the $T_{\text {hot }}-T_{\text {cold }}$ interval define the limits of these two zones. The cold zone comprises from the lower sensor to the position $z_{1}$ (see Figure $6 \mathrm{~b}$ ) where temperature is $15 \%$ higher than $T_{\text {cold }}$. The hot region comprises from height $z_{2}$, with temperature $15 \%$ lower that $T_{h o t}$, to the upper temperature sensor. Intervals are defined by the cold-hot temperature interval.

The calculation of $I_{1 L}$ sums the energy that could be stored in the cold zone and the energy that could be delivered from the hot zone. This sum is compared with one high value that considers the mass of the tank between $z_{T 1}$ and $z_{T 21}$ and the difference of enthalpies corresponding to the design hot and cold temperatures $T_{H}$ and $T_{C} . I_{1 L}$ can be evaluated from the temperature profile through:

$$
I_{1 L}=\frac{\sum_{j=j T 21}^{j_{z 1}} m_{j}\left(h_{H}-h_{j}\right)+\sum_{j=j_{z 2}}^{j_{T 1}} m_{j}\left(h_{j}-h_{L}\right)}{\sum_{j=j_{T 21}}^{j_{T 1}} m_{j}\left(h_{H}-h_{L}\right)}
$$

where $j z 1$ and $j z 2$ are the cell numbers corresponding to heights $z_{1}$ and $z_{2}$ respectively (see Figure $6 \mathrm{~b}$ ). Stratification index $I_{1 L}$ has been defined based on energy considerations with the aim of analyse the effect of the quality of stratification in both the hot and cold zones of the tank.

\subsubsection{Stratification Index Based on the Exergy Analysis}

This stratification index can be considered as a Second Law Index: $I_{2 L}$. The dead state of the water with a temperature $T_{0}$ corresponds to ambient temperature. Contribution from recovery of potential gravitational energy is not considered in exergy evaluation. The value of the exergy $A$ of the water is obtained by the ideal Carnot thermodynamic power cycle cooling down the fluid till the ambient temperature:

$$
A=m\left(\left(h-h_{0}\right)-\bar{c}_{p} T_{0} \ln \left(\frac{T}{T_{0}}\right)\right)
$$

Temperatures for this formulation are in the Kelvin scale. The specific enthalpy of liquid water at ambient temperature is $h_{0}$. An approach was assumed with the mean value of the specific heat capacity $\bar{c}_{p}$, for which the temperature evaluation was performed at the geometric mean between $T_{M}$ and $T_{0}$. The exergy corresponding to the temperature profile in the tank is calculated by summing the value of this property for each cell position between immersion temperature sensors $T_{1}$ and $T_{21}$.

$$
A_{R}=\sum_{j=j_{T 21}}^{j_{T 1}} m_{j}\left(\left(h_{j}-h_{0}\right)-\bar{c}_{p} T_{0} \ln \left(\frac{T_{j}}{T_{0}}\right)\right)
$$

The Second Law Index $\left(I_{2 L}\right)$ evaluates the stratification quality comparing the actual profile with two extreme situations, best and worst stratified: the totally stratified and the totally mixed profiles. The totally stratified has one perfect step with design temperatures. The totally mixed has one single temperature, without any step, as shown in Figure $6 \mathrm{~b}$, but the three profiles provide the same stored energy in the tank. 
Totally mixed and totally stratified profiles are deduced from the actual one, assuming the same stored energy $\left(Q_{s t}\right)$ being accumulated in the tank sections between temperature sensors for the three profiles:

$$
\begin{gathered}
\text { Actual : } Q_{s t}=\sum_{j=j_{T 21}}^{j_{T 1}} m_{j} h_{j} \\
\text { Totally mixed : } Q_{s t}=\sum_{j=j_{T 21}}^{j_{T 1}} m_{j} h_{t m} \\
\text { Totally stratified : } Q_{s t}=m_{L} h_{L}+m_{H} h_{H}
\end{gathered}
$$

Temperature for the totally mixed profile and position of the step for the totally stratified profile are calculated from Equations (9) and (10) respectively. The Second Law index $I_{2 L}$ is obtained from the exergy contained in the tank between temperature sensors for the three profiles ( $A_{\text {actual }}$-actual profile; $A_{t m}$-totally mixed profile; $A_{t s}$-totally stratified profile).

$$
I_{2 L}=\frac{A_{\text {actual }}-A_{t m}}{A_{t s}-A_{t m}}
$$

\subsubsection{Thermocline Mean Temperature Gradients}

During the calculation of thermocline width and $I_{1 L}$ the positions and temperatures of thermocline extremes were found. This information allows us to obtain easily two thermocline gradients that are candidates to be good indicators of stratification behaviour.

Mean temperature gradient from thermocline width calculation corresponds to the region where $5 \%$ of temperature interval was taken off from thermocline extremes (see Figure 4a). It is defined as $M T G_{90}$ and represents mean slope in great part of thermocline region.

Mean temperature gradient from $I_{1 L}$ calculation corresponds to one smaller region where $15 \%$ of interval was taken off from each side. It represents the gradient in the central zone of the thermocline, being defined as $M T G_{70}$.

\section{Results and Discussion}

The results of calculation of these parameters corresponding to the $24 \mathrm{~h}$ period represented in Figure 3, are plotted in Figure 7.

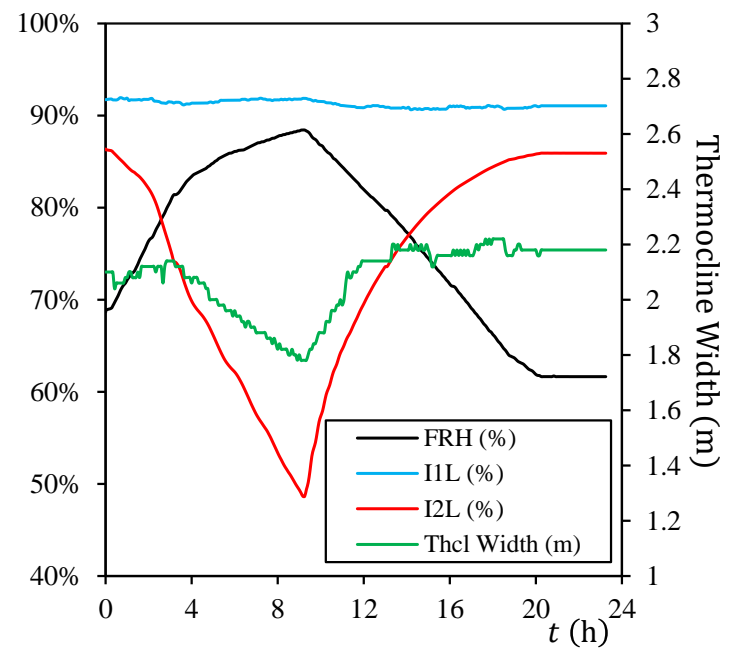

(a)

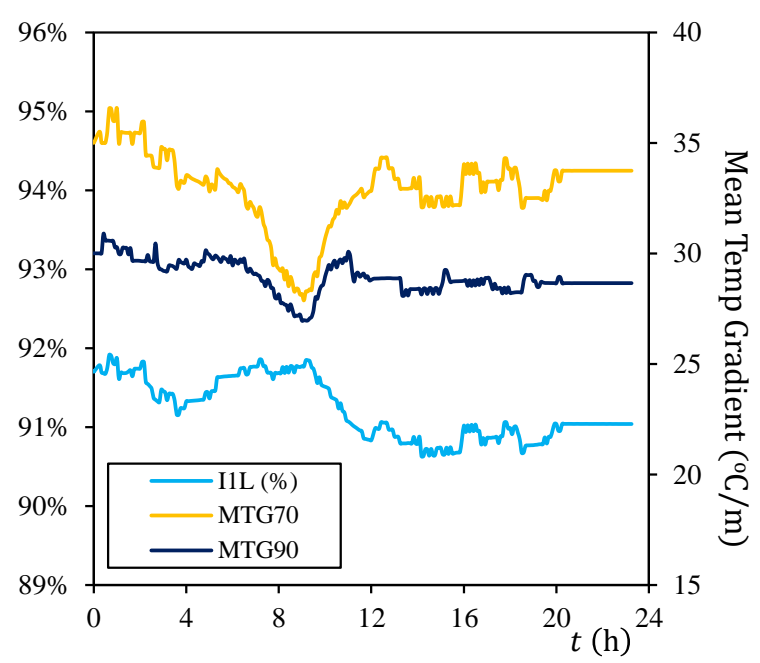

(b)

Figure 7. Results of: (a) FRH, $I_{1 L}, I_{2 L}$ and thermocline width; (b) $I_{1 L}$, and Mean Temperature Gradients, for the $24 \mathrm{~h}$ period in Figure 3. 
The value of index $I_{1 L}$ has low variation in Figure 7a. It varies in an small interval that can be barely appreciated in its scale, that has been adjusted to show variation in $I_{2 L}$ and $F R H$. Results of $I_{1 L}$ are also represented in Figure $7 \mathrm{~b}$ with an adapted scale.

As it was shown in Figure 3, at the end of the charge period, thermocline region reaches the lower temperature sensor T21. That matches with the higher $F R H$. Index $I_{2 L}$ shows low values for extreme values of $F R H$. When the tank is near totally charged or discharged and thermocline region reaches lowest or highest region respectively, the value of this parameter drops dramatically.

Besides $I_{1 L}$, Figure $7 \mathrm{~b}$ represents Mean Temperature Gradients of thermocline: MTG90 and $M T G_{70}$. Mean gradients are found around $28{ }^{\circ} \mathrm{C}$ for the full thermocline region and around $35^{\circ} \mathrm{C}$ in the central more stepped zone of the thermocline. There is an obvious relation of gradients with the thermocline width, which shows a very similar behaviour. The valley in the moment of high FRH corresponds to the incomplete thermocline representation in that situation. This indicates the convenience of avoid extremely charged or discharged situations in the $I_{2 L}$ analysis, although index $I_{1 L}$ do not seem as much sensible to these situations.

\subsection{Generation of Temperature Double Steps}

The combination of buoyancy and forced movement determines the configuration of temperature profile. Bad regulation of the charge process can cause water entering the upper diffuser with lower temperature than desired. With adequate high temperature, water remains in the upper zone, promoting near uniform displacement of central sections. Nevertheless, colder water descends mixing and cooling the full hot section down until thermocline region. That is the change in temperature profile from situation in Figure $8 \mathrm{~b}$ to profile in Figure 8c. Figure 8 represents the irregular charging process and the formation of the double step temperature profile. With the upper zone colder, new hot water will enter remaining in the upper zone and concluding the formation of this irregular temperature profile.

Methods for determination of stratification index $I_{1 L}$ or the thermocline width, as they were described before, can provide unreal results when applied under these conditions. Double steps are stable, corrected when the full hot section exits and new regular profile is generated. Charging colder water could mix and generate one uniform part of the hot section, but once the double step was generated in a conventional device it would not be possible to create a totally uniform hot section with higher thermal level than the minimum in that part. In the studied plant, this imprecise management of the thermal storage was only observed in the hot section during charge process. Control of cold inlet during discharge was more precise, then irregular double temperature steps in the cold zone were not observed but could be generated if hotter water entered the lower diffuser during discharge process.

Formation of double step profiles consists of two main stages. One first stage involves the entrance of water with lower enthalpy through the upper diffuser causing the mixing and decrease of the temperature of the full hot section. The second stage occurs when water enters again with its proper high thermal level giving rise to the double step appearance. The effect of this first stage can be observed in the temperature profile of the monitored sections between $3 \mathrm{~h}$ and $8 \mathrm{~h}$ in Figure 8 . At $8 \mathrm{~h}$ the double step appears and moves down until the end of this charging period, at $16 \mathrm{~h}$.

Figure 9 shows the evolution of the calculated parameters during this period. First and Second Law indices $I_{1 L}, I_{2 L}$ show changes during this process. The value of $I_{1 L}$ decreases while $I_{2 L}$ shows a valley returning later to previous values, despite the double step is still active.

During this period, the Fraction of Recoverable Heat, $F R H$, grows as expected in charging periods. Since it is not an index related with the stratification, no sensitiveness can be appreciated to the double step formation. 


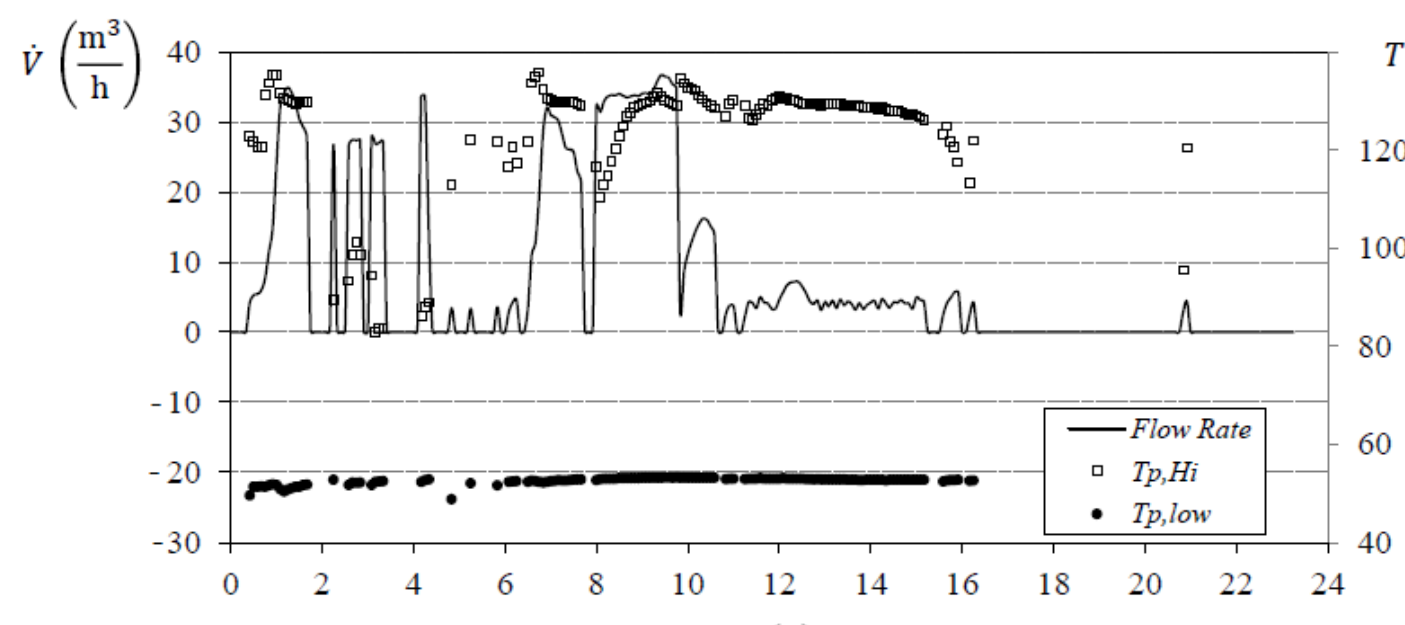

(a)

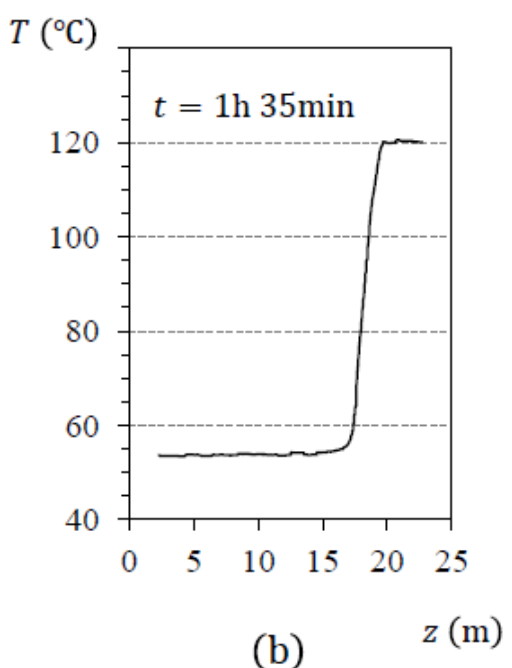

(b)

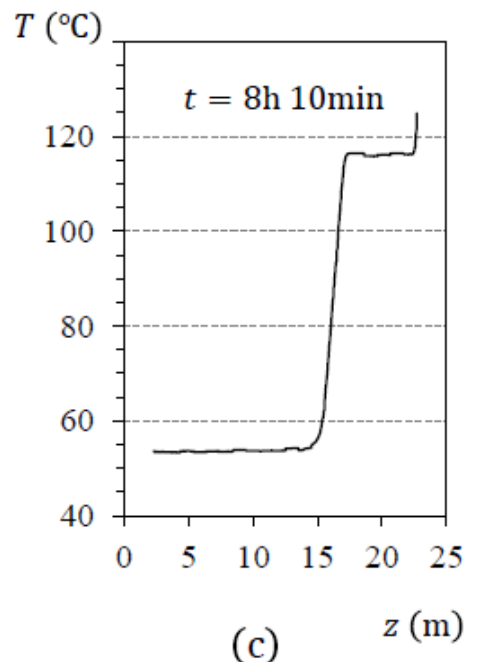

(c) $t(\mathrm{~h})$

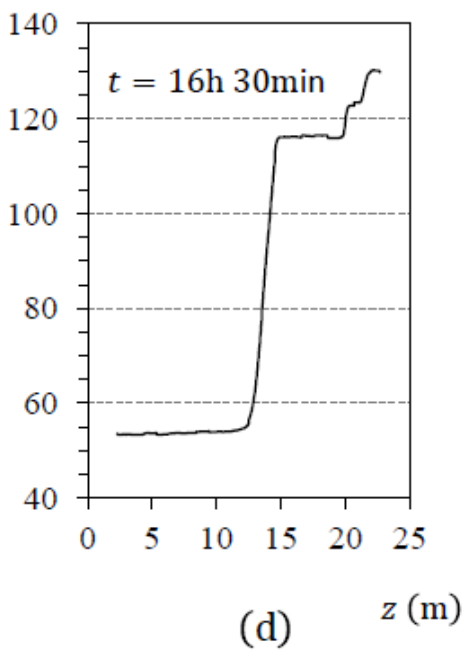

(d)

Figure 8. (a) Flow rate and pipe temperatures in a $24 \mathrm{~h}$ period with double temperature step generation. Temperature profiles at: (b) $1 \mathrm{~h} 30 \mathrm{~min}$; (c) after $8 \mathrm{~h}$; when colder water inlet promoted temperature decrease and sensor detects hotter water (d) after the formation of double temperature step.

The effect of changes in temperature profile can be clearly appreciated in the calculated thermocline width in Figure 9a. The thermocline width decreases suddenly with the first entrance of colder water at $3 \mathrm{~h}$, due to the decrease in the thermal level of the hot section. This also causes the rising of the $90 \%$ Mean Temperature Gradient $M T G_{90}$. The $70 \%$ Mean Temperature Gradient $M T G_{70}$ also increases its value, but it shows the main increase at $8 \mathrm{~h}$ coinciding with the double step appearance. One conclusion rises stating that the decrease of thermocline width or increase of Mean Temperature Gradient can be related with the formation of double steps. Extreme positions of the thermocline can also generate low values of thermocline width as could be observed before (see Figure 7).

In this period, the double step appeared but did not move down the tank significantly. When this happens, the algorithms that detect the thermocline region fail, finding the median of the hot region in a different value causing sudden changes in the thermocline width and stratification indices. Situations with double step will be excluded in the search of more general conclusions about the stratification behaviour in this TTES tank. 


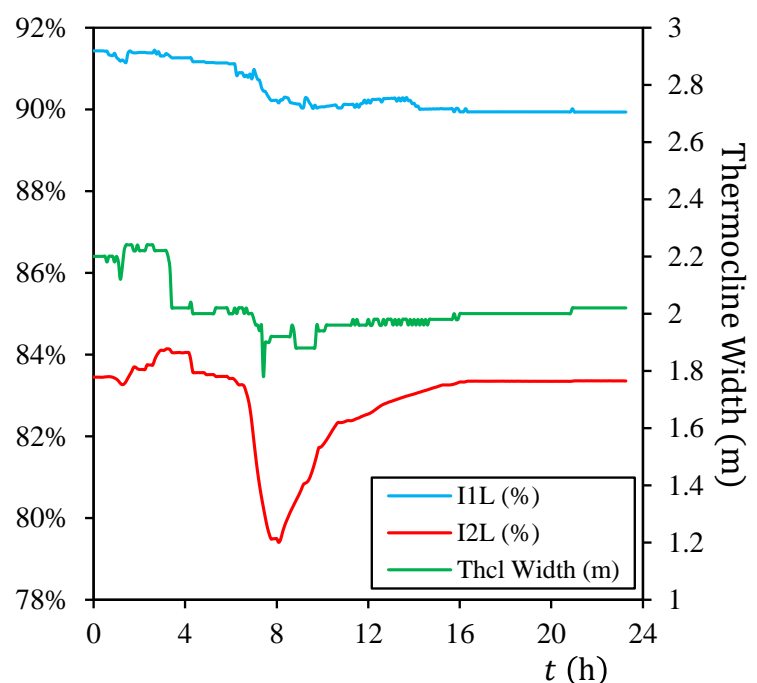

(a)

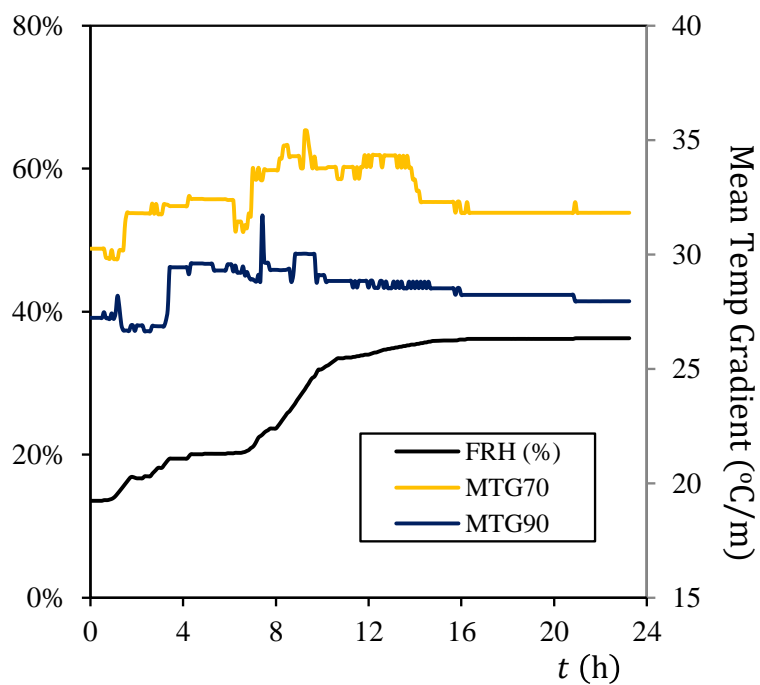

(b)

Figure 9. Results of: (a) $I_{1 L}, I_{2 L}$ and thermocline width; (b) $F R H$, and Mean Temperature Gradients, for the double temperature step formation period in Figure 8.

\subsection{Distribution of the Results}

The study of results is based on a dataset from the plant data acquisition system corresponding to 24 days. The data was processed as explained before and the calculations are based on the detailed enhanced profiles obtained by displacement analysis. Enhanced profiles allow a more precise study of the thermocline region. Data corresponding to instants without good knowledge of the preceding period were excluded. This information is needed to generate the enhanced profile through displacement analysis. During storage periods with null mass flow rate, the profile does not change either, then these periods are also excluded. Fails in registrations and subsequent period exclusion, together with storage periods not considered, have left available a dataset of 4542 instants.

Frequency in discrete interval values of the most significant parameters are presented in Figure 10 for: Fraction of Recoverable Heat, FRH; First Law Index, $I_{1 L}$, Second Law Index, $I_{2 L}$; thermocline widht; $90 \%$ and $70 \%$ Mean Temperature Gradients, $M T G_{90}$ and $M T G_{70}$. The scales in interval distribution for $F R H, I_{1 L}$ and $I_{2 L}$ are in terms of fraction values $0 \div 1$ despite these parameters were also expressed in percentage before. Both scales are valid being this chosen for the sake of clarity.

Distribution of $F R H$ is quite uniform with some preference in values between 65 and $75 \%$ charge. Absence of $95 \div 100 \%$ values is due to calculation procedure involving definition of recoverable and storable therms. The distribution indicates that the operation takes advantage of the full tank capacity with a more frequent use around $70 \%$.

The First Law Index $I_{1 L}$ has a clearly predominant value around 0.92 , being its distribution very concentrated around this value. Its range is between 0.8 and 0.96 with small variation, which agrees with the observation of this index behaviour in Figures 7 and 9 .

The Second Law Index $I_{2 L}$ has more variable behaviour with a wide range in its value and more uniform distribution. It is more sensible than $I_{1 L}$ to changes in temperature profile. This also matches with its observed behaviour in Figures 7 and 9.

The thermocline width has a predominant value, being the most frequent in the interval $2.2 \div 2.4 \mathrm{~m}$. Thermocline width is with a frequency higher than $70 \%$ in the range between 2 and $2.6 \mathrm{~m}$. It is interesting to observe that three small peaks appear with high thermocline width values, situated around 3.6, 6.0, and $7.2 \mathrm{~m}$. These are due to periods when double step temperature profiles appeared causing fails in determination of thermocline region. Very low widths below $2.0 \mathrm{~m}$ correspond to extreme positions of the thermocline. 
$M T G_{90}$ is frequently in values between 24 and $30{ }^{\circ} \mathrm{C}$; the central region is more stepped with predominant $M T G_{70}$ values between 29 and $37 \frac{{ }^{\circ} \mathrm{C}}{\mathrm{m}}$. Outsider values of $M T G_{90}$ are related with double temperature step situations. Temperature slope parameters are sensible to periods of double temperature steps or extreme thermocline positions.
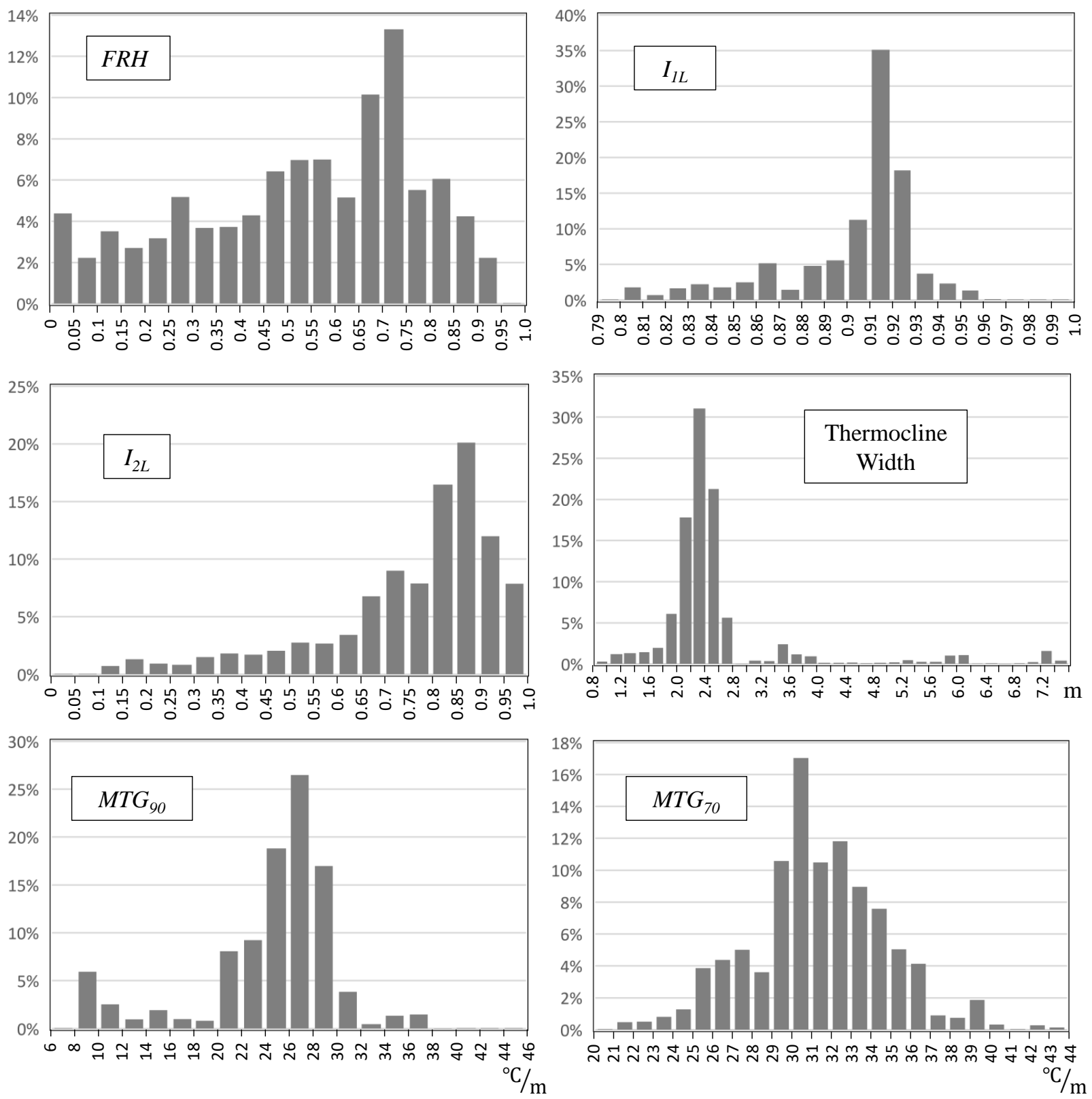

Figure 10. Discrete probability distribution of calculated parameters.

\subsection{Correlation of Stratification Indicators}

The ability of First and Second Law Indices $I_{1 L}$ and $I_{2 L}$ to predict thermocline stratification is studied by means of their correlation with the mean temperature gradients $M T G_{90}$ and $M T G_{70}$. First, the dataset is refined again to exclude the situations with extreme thermocline positions or when double step temperature profiles appear. The studied data corresponds to values of $F R H$ between 0.25 and 0.75 and thermocline widths between 2.0 and $2.7 \mathrm{~m}$. The available dataset after this selection contains data corresponding to 2425 instants. 
First of all, comparison of First against Second Law Indices was performed. Results are shown as the boxplot in Figure 11 drawn from the classification of $I_{1 L}$ according to uniform distribution of $I_{2 L}$ in 21 intervals between its extreme values. The central marks in each box indicates the median. The bottom and top edges of the box are in the 25 and 75 percentiles. The whiskers extend to the extreme data values and circles represent values beyond extremes, known as outliers. The maximum extreme value distance over top box edge or below bottom box edge is 1.5 times the difference between 75 and 25 percentiles. Values farther than this maximum distance are considered as outliers. Figure 11 shows a trend in correlation of First and Second Law indices. The lower values of $I_{1 L}$ occur for lower values of $I_{2 L}$, keeping the trend for the higher values of both indices. Higher dispersion of $I_{1 L}$ is found for the $I_{2 L}$ interval between 0.4 and 0.5 . Second Law index has a bigger interval of variation, between 0.3 and 0.94 , while $I_{1 L}$ varies between 0.8 and 0.93 . This analogue behaviour indicates that similar analysis could be obtained from both indices.

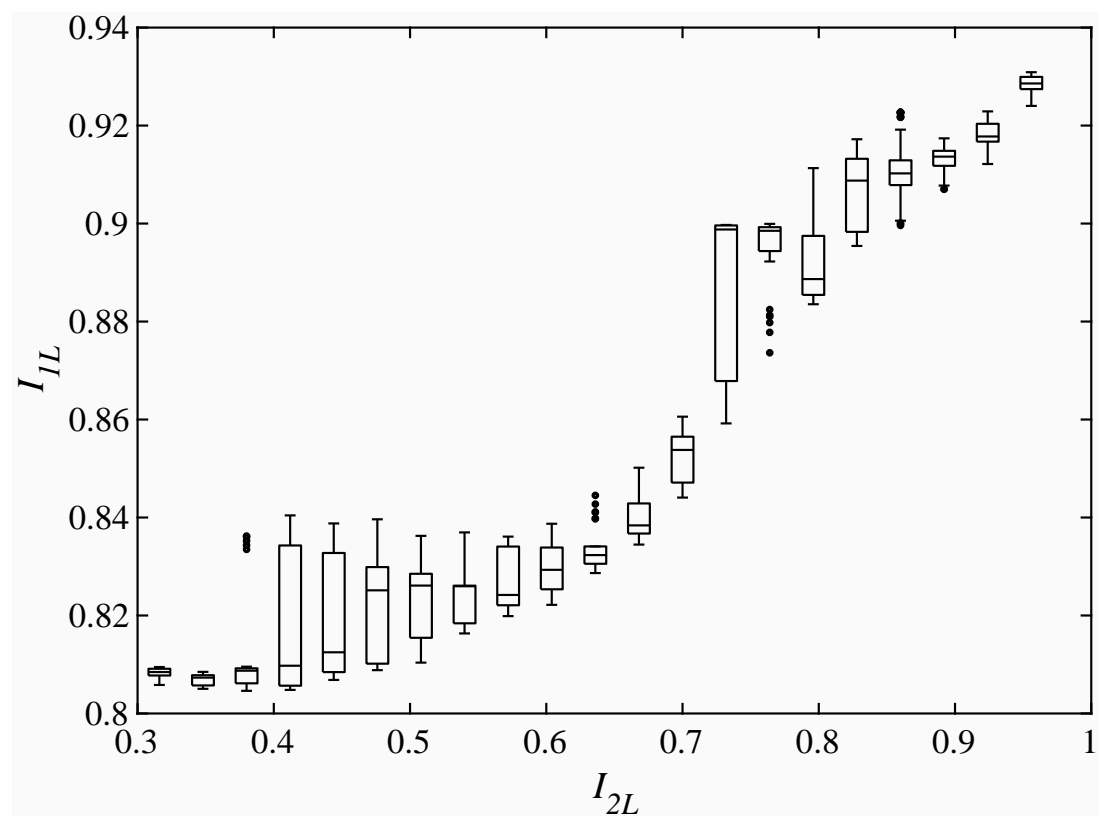

Figure 11. Boxplot representation of First Law Index $I_{1 L}$ against Second Law Index $I_{2 L}$.

TTES facilities base their capacity in the stratification. The Mean Temperature Gradients represent the slope of temperature in height. Situations of good stratification are identified with high $M T G_{90}$ and $M T G_{70}$ values, letting $M T G_{70}$ for the temperature slope in the central thermocline region and $M T G_{90}$ for a wider region.

The ability of First and Second Law indices to describe the stratification state in a thermocline thermal storage tank is checked by means of the analysis of Mean Temperature Gradients against them. In Figure 12 the boxplot corresponding to these comparisons is represented. The representation setup is equivalent to the plot in Figure 11. The same dataset with 2425 instants is also being represented. One main pattern is observed corresponding to one step in MTG situated in medium values of stratification indices. MTG are grouped around their higher values when $I_{2 L}$ is over 0.73 or $I_{1 L}$ over 0.87 , and their lower values happen below these step values of First and Second Law stratification indices. Values are dispersed, but the general pattern is clear. Under the rational assumption of better stratification for more stepped temperature gradients, it seems that $I_{1 L}$ and $I_{2 L}$ as they were defined show in this case better stratification over values of $87 \%$ and $73 \%$ respectively. The behaviour of central $M T G_{70}$ or wider $M T G_{90}$ is shown similar with both indices. The values of 27 and $33{ }^{\circ} \mathrm{C}$ for $M T G_{70}$ and 22 and $27{ }^{\circ} \mathrm{C}$ for $M T G_{90}$ are indicatives of the lower and higher stratification situations. It should be remarked that these arguments are valid for situations where the thermocline position is centred in the tank height and no double temperature step is present in the thermal storage system. 

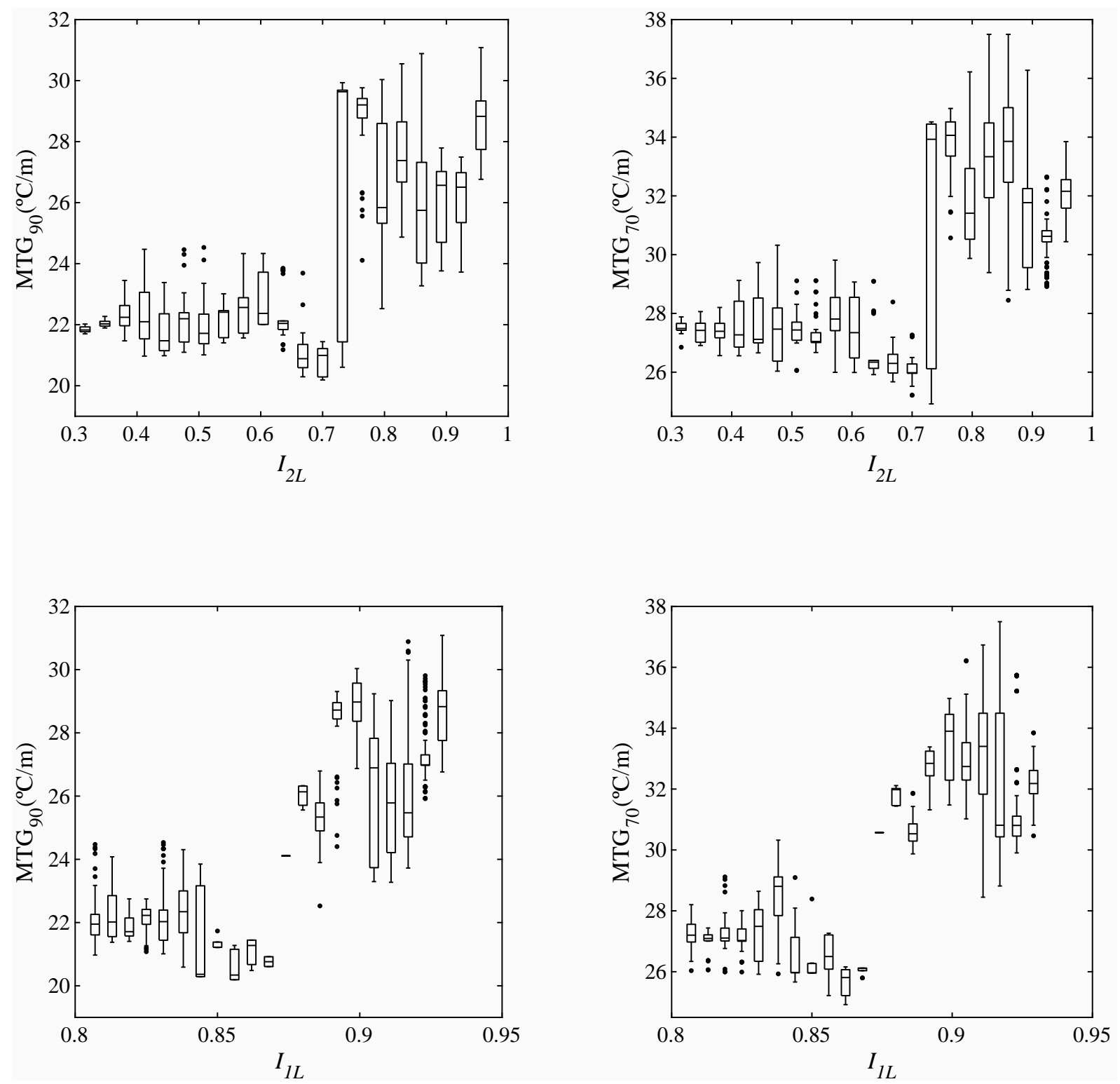

Figure 12. Correlation of Mean Temperature Gradients relative to $90 \%$ and $70 \%$ of the temperature difference between $T_{h o t}$ and $T_{\text {cold }}$ against First and Second Law Indices $I_{1 L}$ and $I_{2 L}$.

\section{Conclusions}

The study of the thermocline thermal energy storage systems has been proposed starting from real data acquired from the control system of one thermal storage facility. The tank is situated between one combined heat and power unit and one industrial drying process, matching thermal energy availability and process demand. The raw mass flow rate and temperature data have been treated to refine and adapt the information with the aim of studying the stratification phenomenon in this facility.

The first analysis shows that the scheme of charge, discharge, and storing periods is irregular and based on the delivery of generated energy and the process demand. There are no full charge-discharge cycles but different combinations of partial energy transports. For this reason, the analysis of system performance is not faced through efficiency parameters, but stratification indices based on information at each instant. The aim in a thermocline thermal storage system is to introduce water at constant temperature through upper and lower entrances. Although the mass flow rates are regulated to get this, punctual inlets with different temperature cause irregularities in the temperature profile. This can be acceptable for the process but has an influence in the performance of the storage system. 
The data treatment of temperature displacement has allowed the generation of detailed enhanced temperature profile. Enhanced profiles were used for the study of the stratification in the thermocline section. Displacement of temperature profile also provides the height of the effective outlet positions at 1.04 and $23.56 \mathrm{~m}$ in the $25 \mathrm{~m}$ high tank. This results were obtained from situations when the thermocline gets upper and lower positions. The displacement simulates the forced tank water movement, but buoyancy mixing in the hot zone is observed when colder water enters through the upper pipe. This generates one uniform colder zone and ulterior double step temperature profile.

Stratification indices were taken from literature and adapted to calculate with this data format. The detailed enhanced temperature profiles were used with data from sections between temperature sensors, since uncertainty beyond these positions did not allow considering the tank extremes. Fraction of Recoverable Heat, thermocline width, First Law Index, and Second Law Index were the main calculated parameters. Thermocline Mean Temperature Gradients with two temperature intervals were also obtained.

The values of these parameters have been represented during two representative periods. One period has been firstly considered consisting of charge, discharge, and store phases. This period also includes the situation of nearly full charge with thermocline in the lowest region. The second selected period includes formation of double step temperature profile. Results of First and Second Law indices, thermocline width and Mean Temperature Gradient show that Second Law index has higher variability than First Law index. Both, First and Second Law indices are sensible to extreme thermocline positions and double step temperature profiles. Thermocline width and Mean Temperature Gradients have parallel behaviour. They are also sensible to extreme thermocline positions and double steps. To analyse stratification, these conditions were eliminated from the study of variables correlation. The results show that there is a positive relationship between values of First and Second Law indices. Mean Temperature Gradients in central thermocline positions without double steps have been assumed as good indicators of stratification. First and Second Law stratification indices show a parallel behaviour with step values in 0.87 and 0.73 , respectively. Lower indices correspond to low thermocline temperature gradients, higher indices correspond to higher gradients.

This study concludes that First and the Second Law indices can be used to estimate the quality of the stratification in thermocline thermal energy storage indices. Nevertheless, high dispersion was observed in the calculated parameters, then more advanced multivariate analysis can be applied to better correlate the results. These more advanced techniques go beyond the scope of this study but will surely be applied soon to get deeper knowledge from this valuable data. Consideration of stratification quality in thermal energy storage devices integrated in energy management systems is one of the future advances in this field. This is the main future application in this research line.

Dissemination of practical knowledge obtained from one real plant data fulfils another important objective of this study. It has been observed that one thermal storage plant clearly designed to operate in single thermocline mode can result in no perfect practical twotemperature performance. It seems that this does not disturb the operation of the process load. Nevertheless, other stratification thermal storage systems exist that allow different temperature storages. Valves and pipe system with variable inlet height are possible, reducing the risk of fluid mixing in the hot sections. When water mixing happened, caused by colder water entering the tank, a sudden decrease in the parameter based on Second Law was observed. Once this mixing occurs, it is not easy to correct it. One possible plant improvement could consist in the addition of one parallel system with different inlet heights to correct this situations.

The data treatment from one conventional energy storage system has helped to confirm usefulness of parameters from literature in the evaluation of stratification in the tank. The thermocline has demonstrated to be very stable in such large systems and the facility has shown very good performance fulfilling its objective. 
Author Contributions: Conceptualisation, F.J.F. and I.M.S.; methodology, F.J.F., J.D. and M.B.F.; software, F.J.F. and J.D.; validation, M.B.F. and I.M.S.; formal analysis, M.B.F.; investigation, F.J.F. and J.D.; resources, I.M.S.; data curation, F.J.F.; writing—original draft preparation, F.J.F. and J.D.; writing-review and editing, M.B.F.; visualisation, J.D.; supervision, M.B.F. and I.M.S. All authors have read and agreed to the published version of the manuscript.

Funding: This research received no external funding.

Institutional Review Board Statement: Not applicable.

Informed Consent Statement: Not applicable.

Data Availability Statement: Not applicable.

Conflicts of Interest: The authors declare no conflict of interest.
Abbreviations
The following abbreviations are used in this manuscript:
TES Thermal Energy Storage
CHP Combined Heat and Power
TTES Thermocline Thermal Energy Storage
FRH Fraction of Recoverable Heat
MTG Mean Temperature Gradient

\section{References}

1. Zalba, B.; Marín, J.M.; Cabeza, L.F.; Mehling, H. Review on thermal energy storage with phase change: Materials, heat transfer analysis and applications. Appl. Therm. Eng. 2003, 23, 251-283. [CrossRef]

2. Oró, E.; Chiu, J.; Martin, V.; Cabeza, L.F. Comparative study of different numerical models of packed bed thermal energy storage systems. Appl. Therm. Eng. 2013, 50, 384-392. [CrossRef]

3. Dincer, I.; Dost, S.; Li, X. Performance analyses of sensible heat storage systems for thermal applications. Int. J. Energy Res. 1997, 21,1157-1171. [CrossRef]

4. Zurigat, Y.; Ghajar, A. Heat Transfer and Stratification in Sensible Heat Storage Systems; Dincer, I., Rosen, M.A., Eds.; Thermal Energy Storage Systems and Applications; John Wiley and Sons: Chichester, UK, 2002; pp. 259-301.

5. Verda, V.; Colella, F. Primary energy savings through thermal storage in district heating networks. Energy 2011, 36, 4278-4286. [CrossRef]

6. Nuytten, T.; Claessens, B.; Paredis, K.; Bael, J.V.; Six, D. Flexibility of a combined heat and power system with thermal energy storage for district heating. Appl. Energy 2013, 104, 583-591. [CrossRef]

7. Christidis, A.; Koch, C.; Pottel, L.; Tsatsaronis, G. The contribution of heat storage to the profitable operation of combined heat and power plants in liberalized electricity markets. Energy 2012, 41, 75-82. [CrossRef]

8. Smith, A.D.; Mago, P.J.; Fumo, N. Benefits of thermal energy storage option combined with CHP system for different commercial building types. Sustain. Energy Technol. Assessments 2013, 1, 3-12. [CrossRef]

9. Jordan, U.; Furbo, S. Thermal stratification in small solar domestic storage tanks caused by draw-offs. Sol. Energy 2005, 78, 291-300. [CrossRef]

10. Yang, Z.; Garimella, S.V. Thermal analysis of solar thermal energy storage in a molten-salt thermocline. Sol. Energy 2010, 84, 974-985. [CrossRef]

11. Li, P.; Lew, J.V.; Karaki, W.; Chan, C.; Stephens, J.; Wang, Q. Generalized charts of energy storage effectiveness for thermocline heat storage tank design and calibration. Sol. Energy 2011, 85, 2130-2143. [CrossRef]

12. Palacios, E.; Admiraal, D.; Marcos, J.; Izquierdo, M. Experimental analysis of solar thermal storage in a water tank with open side inlets. Appl. Energy 2012, 89, 401-412. [CrossRef]

13. Cocco, D.; Serra, F. Performance comparison of two-tank direct and thermocline thermal energy storage systems for 1 MWe class concentrating solar power plants. Energy 2015, 81, 526-536. [CrossRef]

14. Mawire, A.; Taole, S.H. A comparison of experimental thermal stratification parameters for an oil/pebble-bed thermal energy storage (TES) system during charging. Appl. Energy 2011, 88, 4766-4778. [CrossRef]

15. Bindra, H.; Bueno, P.; Morris, J.F.; Shinnar, R. Thermal analysis and exergy evaluation of packed bed thermal storage systems. Appl. Therm. Eng. 2013, 52, 255-263. [CrossRef]

16. Singh, H.; Saini, R.; Saini, J. A review on packed bed solar energy storage systems. Renew. Sustain. Energy Rev. 2010, 14, 1059-1069. [CrossRef]

17. Sarbu, I.; Sebarchievici, C. A comprehensive review of thermal energy storage. Sustainability 2018, 10, 191. [CrossRef]

18. Kocak, B.; Fernandez, A.I.; Paksoy, H. Review on sensible thermal energy storage for industrial solar applications and sustainability aspects. Sol. Energy 2020, 209, 135-169. [CrossRef] 
19. Karim, A.; Burnett, A.; Fawzia, S. Investigation of stratified thermal storage tank performance for heating and cooling applications. Energies 2018, 11, 1049. [CrossRef]

20. Abd Majid, M.A.; Muhammad, M.; Hampo, C.C.; Akmar, A.B. Analysis of a Thermal Energy Storage Tank in a Large District Cooling System: A Case Study. Processes 2020, 8, 1158. [CrossRef]

21. Rodríguez-Hidalgo, M.d.C.; Rodríguez-Aumente, P.A.; Lecuona, A.; Legrand, M.; Ventas, R. Domestic hot water consumption vs. solar thermal energy storage: The optimum size of the storage tank. Appl. Energy 2012, 97, 897-906. [CrossRef]

22. Chandra, Y.P.; Matuska, T. Stratification analysis of domestic hot water storage tanks: A comprehensive review. Energy Build. 2019, 187, 110-131. [CrossRef]

23. Haller, M.Y.; Cruickshank, C.A.; Streicher, W.; Harrison, S.J.; Andersen, E.; Furbo, S. Methods to determine stratification efficiency of thermal energy storage processes-Review and theoretical comparison. Sol. Energy 2009, 83, 1847-1860. [CrossRef]

24. Njoku, H.; Ekechukwu, O.; Onyegegbu, S. Comparison of energy, exergy and entropy generation-based criteria for evaluating stratified thermal store performances. Energy Build. 2016, 124, 141-152. [CrossRef]

25. Rosen, M.A. The exergy of stratified thermal energy storages. Sol. Energy 2001, 71, 173-185. [CrossRef]

26. Rosen, M.A.; Tang, R.; Dincer, I. Effect of stratification on energy and exergy capacities in thermal storage systems. Int. J. Energy Res. 2004, 28, 177-193. [CrossRef]

27. Jack, M.W.; Wrobel, J. Thermodynamic optimization of a stratified thermal storage device. Appl. Therm. Eng. 2009, 29, 2344-2349. [CrossRef]

28. Fan, J.; Furbo, S. Thermal stratification in a hot water tank established by heat loss from the tank. Sol. Energy 2012, 86, 3460-3469. [CrossRef]

29. Flueckiger, S.M.; Garimella, S.V. Second-law analysis of molten-salt thermal energy storage in thermoclines. Sol. Energy 2012, 86, 1621-1631. [CrossRef]

30. De Rosa, M.; Carragher, M.; Finn, D.P. Flexibility assessment of a combined heat-power system (CHP) with energy storage under real-time energy price market framework. Therm. Sci. Eng. Prog. 2018, 8, 426-438. [CrossRef]

31. Thombre, M.; Mdoe, Z.; Jäschke, J. Data-Driven Robust Optimal Operation of Thermal Energy Storage in Industrial Clusters. Processes 2020, 8, 194. [CrossRef]

32. Ashrae. Thermal Storage. In Ashrae Handbook 2016: HVAC Systems and Equipment; ASHRAE: Atlanta, GA, USA, 2016.

33. González-Altozano, P.; Gasque, M.; Ibáñez, F.; Gutiérrez-Colomer, R.P. New methodology for the characterisation of thermal performance in a hot water storage tank during charging. Appl. Therm. Eng. 2015, 84, 196-205. [CrossRef]

34. Savicki, D.L.; Vielmo, H.A.; Krenzinger, A. Three-dimensional analysis and investigation of the thermal and hydrodynamic behaviors of cylindrical storage tanks. Renew. Energy 2011, 36, 1364-1373. [CrossRef]

35. Kong, L.; Yuan, W.; Zhu, N. CFD Simulations of Thermal Stratification Heat Storage Water Tank with an Inside Cylinder with Openings. Procedia Eng. 2016, 146, 394-399. [CrossRef]

36. Fernandez-Seara, J.; Uhía, F.J.; Sieres, J. Experimental analysis of a domestic electric hot water storage tank. Part II: Dynamic mode of operation. Appl. Therm. Eng. 2007, 27, 137-144. [CrossRef]

37. Natinal Institute of Standards and Technology (NIST). 2019. Available online: http:/ / www.nist.gov (accessed on 30 November 2020).

38. Bahnfleth, W.P.; Song, J. Constant flow rate charging characteristics of a full-scale stratified chilled water storage tank with double-ring slotted pipe diffusers. Appl. Therm. Eng. 2005, 25, 3067-3082. [CrossRef] 